\title{
Identification of the TP53-induced glycolysis and apoptosis regulator in various stages of colorectal cancer patients
}

\author{
KHAYAL AL-KHAYAL $^{1 *}$, MAHA ABDULLA $^{1 *}$, OMAR AL-OBEED $^{1}$, WAEL AL KATTAN ${ }^{3}$, AHMAD ZUBAIDI $^{1}$, \\ MANSOOR-ALI VAALI-MOHAMMED ${ }^{1}$, ABDULMALIK ALSHEIKH ${ }^{2}$ and REHAN AHMAD ${ }^{1}$ \\ ${ }^{1}$ Colorectal Research Chair, College of Medicine, King Saud University; ${ }^{2}$ Department of Pathology, \\ King Khalid University Hospital; ${ }^{3}$ Department of Surgery, College of Medicine, \\ Al-Faisal University, Riyadh, Kingdom of Saudi Arabia
}

Received October 13, 2015; Accepted November 13, 2015

DOI: $10.3892 / o r .2015 .4494$

\begin{abstract}
The TP53-induced glycolysis and apoptosis regulator (TIGAR) is a p53 target gene known to regulate glycolysis by acting as fructose bis-phosphatase (FBPase) and modulate reactive oxygen species. TIGAR expression has been implicated in oncogenesis and progression of several human cancers. However, TIGAR expression is not known in various stages of colorectal cancer (CRC). There is an increase in the colorectal cancer incidence in Saudi Arabia. We sought to analyze TIGAR expression in this ethnic group. The aim of this study was to investigate the TIGAR expression in colorectal cancer (CRC) patients from Saudi Arabia. Tissue microarray (TMA) was constructed from 22 matched colorectal tumor tissues and adjacent normal tissues. TIGAR expression was examined in TMA slide using immunohistochemistry. TIGAR mRNA was determined in 14 matched tumor tissue and adjacent normal tissue. TIGAR protein expression was also examined in CRC tumor tissues and cell lines. Statistical analyses (t-test) were applied to evaluate the significance of TIGAR expression. TIGAR mRNA level was upregulated significantly in stage II $(\mathrm{p}<0.01)$ and stage III $(\mathrm{p}<0.05)$ when compared to adjacent normal tissue. Immunohistochemical studies revealed that TIGAR expression was increased in colorectal cancer. Strong TIGAR positive staining was found in $68 \%(15 / 22)$ of the tumor samples with nuclear localization. TIGAR staining was found to be significantly increased in early stage (stage I and II) CRC ( $<<0.05)$ and late stage (stage III and IV) CRC $(\mathrm{p}<0.01)$. TIGAR protein was also found to be highly expressed in stage II and III colorectal cancer tissues and CRC cell lines. These findings indicate that TIGAR is highly expressed at the
\end{abstract}

Correspondence to: Dr Rehan Ahmad, Colorectal Research Chair, Department of Surgery, King Khalid University Hospital, College of Medicine, King Saud University, P.O. Box 7805 (37), Riyadh 11472, Kingdom of Saudi Arabia

E-mail: arehan@ksu.edu.sa; rehan.dna@gmail.com

${ }^{*}$ Contributed equally

Key words: colorectal cancer, TP53-induced glycolysis and apoptosis regulator, tissue microarray, immunohistochemistry, gene expression
mRNA and protein levels in colorectal cancer with prominent nuclear localization. TIGAR expression may be used as a bio-marker for detection of colorectal cancer and can be used as a target for developing therapeutics for the treatment of colorectal cancer.

\section{Introduction}

Colorectal cancer is the leading cause of cancer related death globally. Colorectal cancer results from genetic and epigenetic changes in epithelial cells leading to transformation into adenocarcinoma and subsequently metastasis (1). The prognosis of patients with advanced colorectal cancer remains poor and heterogeneous despite advances in the early diagnosis and treatment of colorectal cancer (2). There are no biomarkers recognized for advanced colorectal cancer as a cause for the poor prognosis of patients (3). There is an urgent need for finding markers for the detection of early colorectal cancer.

The p53 tumor suppressor gene plays an important role in response to cellular stress and inhibiting tumor growth by inducing cell cycle arrest, senescence and apoptosis. Loss of p53 function leads to most cancer development (4). The TP53-induced glycolysis and apoptosis regulator (TIGAR) is a p53-inducible gene and has been investigated by gene microarray analysis, and is located on chromosome 12p13-3 $(5,6)$. TIGAR shares similarities with the bisphosphatase domain of phosphofructokinase (PFK-2)/fructose bis phosphatase (FBPase-2) (6). TIGAR functions like FBPase-2, which lead to the depletion of intracellular fructose-2, 6-bisphosphate. Decrease in TIGAR levels have been shown to increase the levels of fructose 2,6 bisphosphate and to enhance the rate of glycolysis (6-8). Hence TIGAR expression results in slowing down the glycolysis pathway. Enhanced TIGAR expression can lead to the diversion of the glycolytic metabolites to alternative metabolic pathways such as hexosamine pathway and pentose phosphate pathway (PPP). The pentose phosphate pathway plays an important role in generating ribose-5-phosphate for nucleotide biosynthesis and the production of NADPH for antioxidant function and fatty acid synthesis. Accumulation of NADPH leads to an increase in intracellular glutathione levels which results in lowering reactive oxygen species (ROS). Most of the studies showed that TIGAR downregulates ROS and 
therefore protects against ROS-induced cell death (6,9-12). The antioxidant functions of TIGAR for cell survival is evident by protection from stress-induced damage during regeneration of intestinal tissue $(13,14)$.

During tumor development the metabolic pathways control redox homeostasis and provide intermediates needed for cell growth. Several studies have indicated that the deregulation of TIGAR expression may contribute to cancer development. As TIGAR lowers ROS and is involved in promoting anabolic pathways and thereby leads to cell survival in tumor microenvironment. Elevated TIGAR expression has been reported in colon, breast cancer and glioblastoma $(11,13,15,16)$. Depletion of TIGAR sensitizes glioma cells in response to DNA damage and induces cellular senescence (8). Similarly in nasopharyngeal cancer cells, inhibition of c-Met decreased TIGAR expression leading to cell death (17), and in another finding, intestinal adenoma with APC deletion in LGR5 ${ }^{+}$intestinal stem cells, mice deficient in TIGAR showed reduced tumor development (18). Understanding the TIGAR expression in various stages of colorectal cancers will be critical in determining its role as a biomarker as well as an attractive target for cancer therapeutics. TIGAR expression could be useful for clinical markers for diagnostic, prognostic and therapeutic applications.

The aim of the present study was to investigate TIGAR expression in colorectal tumor tissue and adjacent normal tissue. This study demonstrates that TIGAR expression was significantly higher in colorectal tumor as compared to adjacent normal tissue. The results further show that there was significant increase in TIGAR expression at mRNA and protein levels in stage II and III colorectal cancer. This is the first report of TIGAR expression in various stages of colorectal cancer. TIGAR can act as an independent biomarker for the detection of colorectal cancer and a therapeutic target for drug discovery.

\section{Materials and methods}

Patient samples. Tumor tissue and normal adjacent tissue of 22 patients with colorectal cancer was included in this study. Patients did not receive any treatment before surgery. Tissue material after resection for colorectal cancer was collected at the Department of Surgery, at King Khaled University Hospital (KKUH), Riyadh, Saudi Arabia between 2012 and 2013. Representative specimens of macroscopically vital, non-necrotic tumor tissue and normal colorectal mucosa, taken $\geq 5 \mathrm{~cm}$ distant from the tumor, were obtained. Specimens were transported on ice to the laboratory and the tissue was washed with ice-cold phosphate-buffered saline (PBS), cut in small pieces, frozen in liquid nitrogen and stored at $-80^{\circ} \mathrm{C}$ until use. Ethical approval for the anonymous use of colorectal tissue was obtained from the KKUH ethics review committee. The patient demographics including age, gender, tumor site and histological stages were recorded in data base according to Union International Contre le Cancer (UICC)-TNM Staging System and grading of CRC in accordance with WHO classification. Histologically adjacent normal tissue from margins of the specimens served as control tissue. All tissue samples were diagnosed and classified by two pathologists.
Tissue microarray (TMA). The construction of tissue microarray (TMA) has been described (19). Formalinfixed paraffin-embedded (FFPE) tissue blocks containing colorectal cancer were retrieved from the archives of the King Khalid University Hospital. The TMA was constructed from FFPE tumor blocks using a manual tissue arrayer (Arraymold kit D IHC World, Woodstock, MD, USA). Invasive carcinoma areas were identified on H\&E stained slides by an expert pathologist. To construct TMA a $1 \mathrm{~mm}$ diameter needle was used to take three cores from each block corresponding to the rich tumor areas detected on the slide. The paraffin TMA blocks were incubated at $37^{\circ} \mathrm{C}$ for $30 \mathrm{~min}$ to enhance the adhesion between the cores and paraffin. TMA blocks were micro-dissected using a Leica semi-automatic microtome, and mounted on glass slides.

Immunohistochemistry. Immunohistochemistry was done as described (20). Paraffin-embedded blocks of tumor tissues and adjacent normal were cut into 5- $\mu \mathrm{m}$ thick sections. Slides were deparaffinized in xylene and rehydrated using a graded ethanol series. Antigen was retrieved by boiling the slides in a microwave oven for $15 \mathrm{~min}$ in $0.01 \mathrm{~mol} / 1$ citrate buffer ( $\mathrm{pH}$ 6.0). Endogenous peroxidase was blocked with a $3 \% \mathrm{H}_{2} \mathrm{O}_{2}$-methanol solution, and the slides were incubated in $10 \%$ normal goat serum for $30 \mathrm{~min}$ to prevent non-specific staining. The tissue sections were then incubated overnight at $4^{\circ} \mathrm{C}$ with primary antibody [TIGAR sc-166291 (1:100 dilution); Santa Cruz Biotechnology, Dallas, TX, USA]. The standard biotin-streptavidin-peroxidase method was then used, and the sections were lightly counterstained with hematoxylin. Breast tumor was used as positive controls for TIGAR. As a negative control, the same procedure was conducted without primary antibody. The expression of TIGAR in tumor and adjacent normal samples was analyzed using the eSlide capture device (ScanScope CS, Aperio Technologies Inc., Vista, CA, USA).

Image analysis. High-resolution, whole-slide digital scans of all TMA glass slides were created with a ScanScope slide scanner (Aperio Technologies, Inc.). The digital slide images were viewed by Aperio viewing software (ImageScope), and analyzed using Aperio image analysis algorithms. In each core, five square fields of a fixed area of $0.2645 \mu \mathrm{m}^{2}$ were randomly selected. The color deconvolution (color separation) algorithm (Aperio Technologies, Inc.) was then run on the selected area, and it generated an intensity range color markup image, segmenting and color-coding different parts of the image according to the intensity of positive staining. The area for each of these four intensity categories (expressed as a percent relative to the total analysis area), together with the average positive intensity and the average optical density, was also given as numerical output. The algorithm output also included a score (0-60) of TIGAR expression based on the percent strong positive and percent medium positive. These values were combined and named as the percent strong positive. The analysis output results were then exported to excel sheets and subjected to statistical analysis, focusing mainly on the percentage of the total positive cells as the parameters to be statistically analyzed and compared. 
Quantitative RT-PCR. cDNA synthesis was performed with $1 \mu \mathrm{g}$ total RNA (21) using the High Capacity Reverse Transcription kit (Applied Biosystems). The cDNA samples were amplified using the SYBR Green qPCR assay kit (Applied Biosystems) and the StepOnePlus real-time PCR system (Applied Biosystems). Primers used for TIGAR analysis are: forward, 5'-CTCCAGTGATCTCATGAG-3'; reverse, 5'-AGACACTGGCTGCTAATC-3'.

Cell culture. Human HT-29, HCT-15, HCT116 and SW620 colorectal cancer cells were grown in DMEM (Invitrogen) containing $10 \%$ heat-inactivated fetal bovine serum, $100 \mu \mathrm{g} / \mathrm{ml}$ streptomycin, $100 \mathrm{U} / \mathrm{ml}$ penicillin and $2 \mathrm{mmol} / \mathrm{l} \mathrm{L}$-glutamine.

Western blotting. Protein samples were isolated from colorectal cancer tissues using PARIS kit (Ambion). Total protein concentration was determined using Bradford protein reagent (Bio-Rad).Soluble proteins were loaded on precast TGX gels and were analyzed by immunoblotting with anti-TIGAR (dilution 1:1,000; Santa Cruz Biotechnology). Reactivity was detected with horseradish peroxidase-conjugated secondary antibodies and chemiluminescence (GE Healthcare). Membrane was developed using C-Digit Blot Scanner (LI-COR, Hamburg, Germany). CRC cell line whole cell lysates were prepared as described (22). Soluble proteins were analyzed by immunoblotting with anti-TIGAR (Santa Cruz Biotechnology) and anti- $\beta$-actin (Sigma). Reactivity was detected with horseradish peroxidase-conjugated secondary antibodies and chemiluminescence (GE Healthcare). Membranes were developed using C-Digit Blot Scanner (LI-COR).

Ethics statement. The study complied with the requirements, and was approved by the Ethics Committee of the King Saud University. Patient consent was obtained for this study.

Statistical analysis. Statistical analysis was performed using Microsoft excel. The means between the two groups were compared using Student's t-test and P-value of $\leq 0.05$ was considered statistically significant.

\section{Results}

Clinico-pathological data of colorectal cancer patients are summarized in Table I. All the tumor samples were adenomas with high grades (grade 2 and 3). Majority of the tumors (90\%) were advanced at stage II and III. Forty percent of the tumor was found located in the colon and rest were in the rectum, sigmoid and recto-sigmoid. Approximately $36 \%$ of the patients had already developed lymph node metastasis.

TIGAR mRNA expression in colorectal cancer. qRT-PCR analyses was performed to determine the expression of TIGAR in 14 paired primary colorectal tumor tissues and matched adjacent normal tissues. TIGAR mRNA was upregulated in colorectal tumor samples compared to adjacent normal tissue from the same patients. TIGAR mRNA was significantly higher in stage II colorectal cancer $(\mathrm{p}<0.01)$ and stage III CRC $(\mathrm{p}<0.05)$ as compared to adjacent normal tissue (Fig. 1). These results demonstrate that TIGAR mRNA was overexpressed in stage II and III tumor samples.
Table I. Clinical characteristics of colorectal cancer patients.

\begin{tabular}{lc}
\hline Variables & Patients \\
\hline Number & 22 \\
Men/women & $11 / 11$ \\
Mean age (range) & $57(36-81)$ \\
Tumor localization & \\
Colon & $9(40 \%)$ \\
Rectum & $2(9 \%)$ \\
Sigmoid & $5(22.7 \%)$ \\
Rectosigmoid & $6(27.3 \%)$
\end{tabular}

Adenocarcinoma

Differentiation grade

Moderately differentiated

$19(86.4 \%)$

Poorly differentiated

$3(13.6 \%)$

Clinical staging

Stage I

Stage II

$12(54.5 \%)$

Stage III

$8(36.4 \%)$

Stage IV

$1(4.5 \%)$

Tumor staging

T2

T3

$17(77.3 \%)$

$\mathrm{T} 4$

$2(9 \%)$

Lymph node status

N0

$14(63.6 \%)$

N1

$6(27.3 \%)$

$\mathrm{N} 2$

$2(9 \%)$

Metastasis

Yes

$8(36.3 \%)$

No

$14(63.6 \%)$

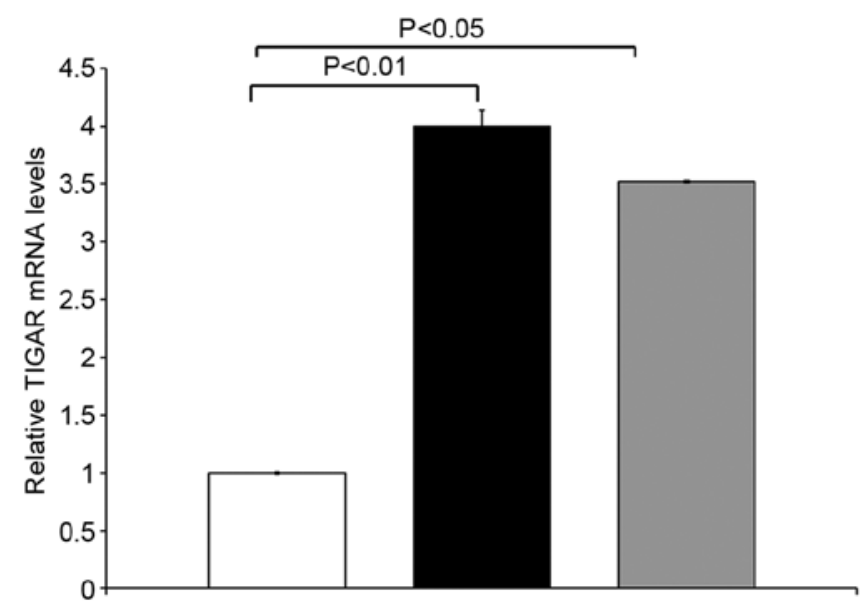

Figure 1. TIGAR mRNA levels were determined by qRT-PCR. The results are expressed as relative TIGAR mRNA levels (mean \pm SD of three determinations) compared with that obtained for GAPDH as a control. Adjacent normal (white bar); stage II (black bar); stage III (grey bar). 

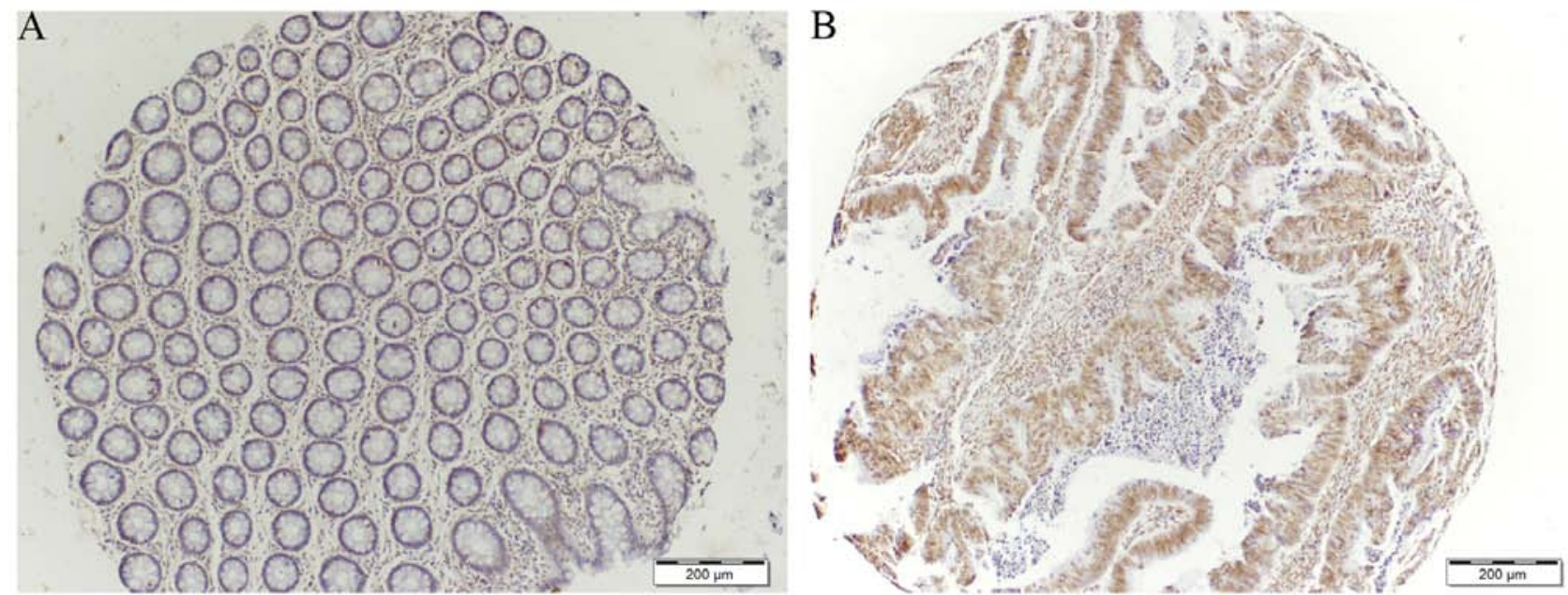

Figure 2. Immunohistochemical staining of tissue microarray cores with TIGAR antibody. Cores demonstrating TIGAR staining in adjacent normal (A) and strong positive TIGAR staining in tumor (B) (x10 magnification).
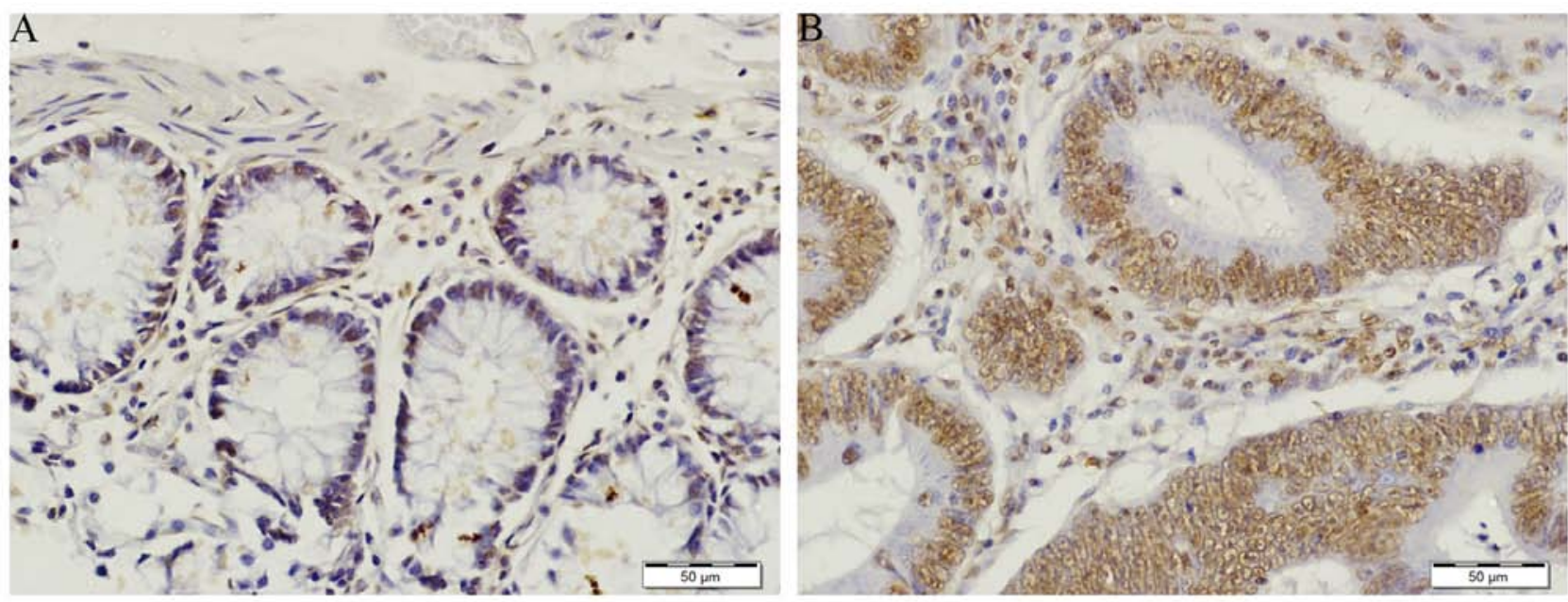

Figure 3. Tissue demonstrating weak TIGAR staining in normal (A) and strong positive TIGAR staining in tumor (B) (x40 magnification).

TIGAR staining in colorectal cancer. TIGAR expression was determined on tissue microarray (TMA) consisting of 22 samples comparing normal and tumor tissue from the same patients. Immunohistochemical staining for TIGAR showed an increase in TIGAR protein in colorectal tumor when compared to adjacent normal tissue (Figs. 2 and 3). Approximately 68\% tumor tissues were strongly positive for TIGAR staining. Weak to moderate TIGAR staining was detected in the adjacent normal tissue, however, positive TIGAR staining was detected in 15 of the 22 (68\%) tumor tissues. Additionally, the entire positive staining observed was found to be mainly with nuclear localization.

Immunohistochemical analysis of TIGAR expression. TIGAR staining was prominent in colorectal tumor as compared to normal adjacent tissue (Figs. 2A and 3A). In normal tissue TIGAR staining was weak (Fig. 3A). TIGAR was highly expressed in colorectal tumor and localized in the nucleus (Figs. 2B and 3B). The strong positive staining of TIGAR was significantly higher in early stage (stage I and II) colorectal cancer $(p<0.05)$. The TIGAR staining was also significantly higher in late stage (stage III and IV) colorectal tumor $(p<0.01)$ (Fig. 4). In agreement with the qRT-PCR data, immunohistochemical analysis confirmed that TIGAR was overexpressed in most of the colorectal tumor tissues as compared to adjacent normal tissue. Taken together, these finding indicated that TIGAR is upregulated in colorectal cancer at both transcriptional and translational levels. These findings demonstrate that TIGAR protein expression was significantly increased in tumor samples, with only weak expression in adjacent normal tissues.

TIGAR expression in CRC patient tissues and cell lines. TIGAR protein detection was carried out in CRC tumor tissues. TIGAR protein was highly expressed in stage II and III colorectal cancer as compared to adjacent normal tissue. TIGAR protein was also highly expressed in metastatic samples (Fig. 5A). We further performed the detection of 


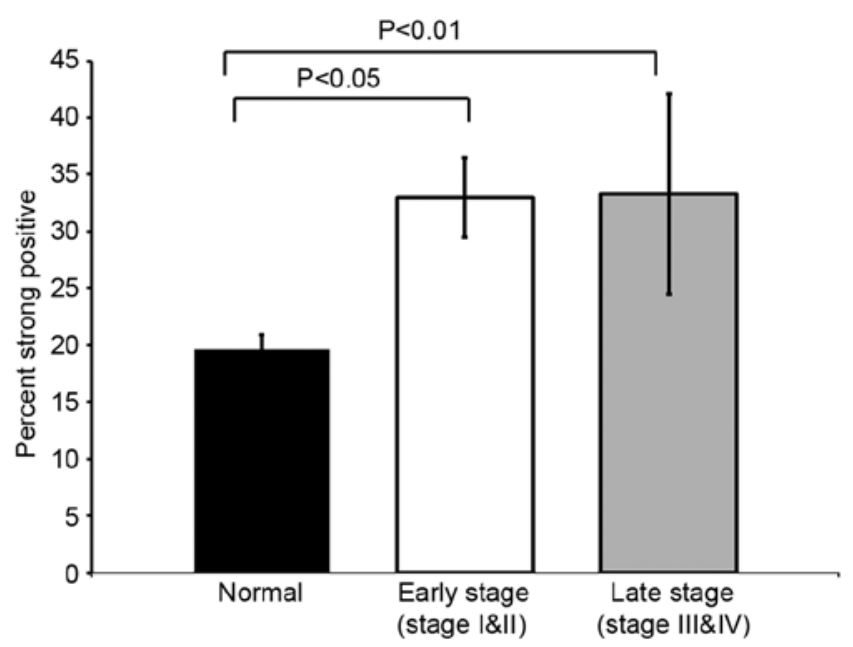

Figure 4 . The percentage of strong positive staining. TIGAR staining analysis in adjacent normal (black bar), early stage CRC (white bar) and late stage CRC (grey bar).

A

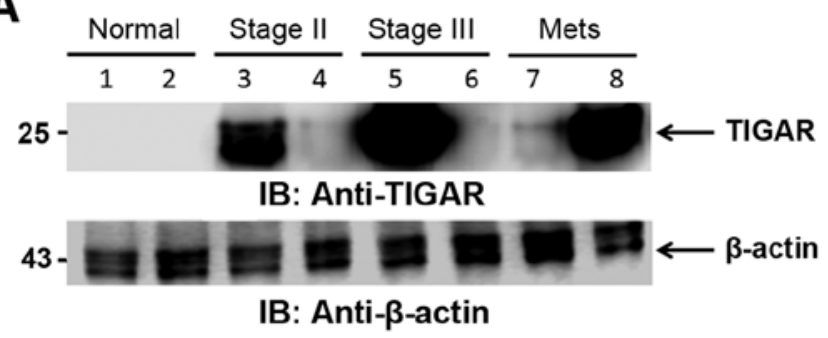

B

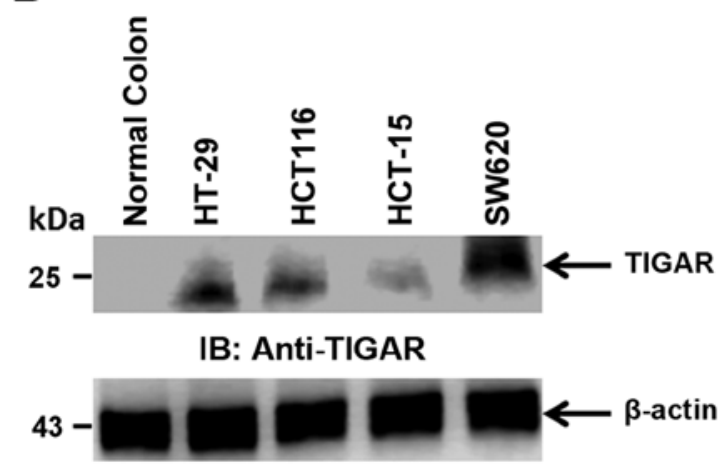

IB: Anti- $\beta$-actin

Figure 5. TIGAR protein expression in CRC tissues and cell lines. (A) Tissue from normal and CRC tumor from stage II and III and metastasis were immunoblotted with indicated antibodies. (B) Lysate from normal, HT-29, HCT116, HCT-15, and SW620 were immunoblotted with indicated antibodies.

TIGAR protein in CRC cell lines. TIGAR protein was found to be expressed in all the CRC cell lines tested. TIGAR protein was expressed in colorectal cancer cell lines HT-29 and HCT116 as compared to normal colon tissue. TIGAR protein expression was higher in colorectal cancer metastatic cell line SW620 as compared to adenocarcinoma cell lines (Fig. 5B). In agreement with TIGAR mRNA and TIGAR staining in tumor tissues, the TIGAR protein was highly expressed in CRC tissues and cell lines. These finding collectively indicated that TIGAR is significantly overexpressed in tumor samples and CRC cell lines.

\section{Discussion}

p53 is a well-known tumor suppressor which prevents the growth and survival of cancer cells during cellular transformation by inducing apoptosis or senescence in response to stress (23). Furthermore, p53 function has been linked to metabolism as well (24). The metabolic activity of p53 is performed by TIGAR. TIGAR, like FBPase-2 deplete fructose-2,6-bisphosphate (F26P2) which is an activator of phosphofructokinase 1 (PFK1) (6). Overexpression of TIGAR has been reported in tumors such as colon cancer (13), breast cancer (15), and glioblastoma $(8,16)$. TIGAR expression has not been reported in colorectal cancer specifically in different stages of colorectal cancer.

The present study investigated the TIGAR mRNA and protein expression in various stages of colorectal cancer patients from Saudi Arabia. This study demonstrated that TIGAR mRNA expression is significantly higher in stage II and stage III colorectal tumor. This increase in TIGAR mRNA is significant in stage II colorectal tumor compared to normal tissue $(\mathrm{p}<0.01)$. Immunohistochemical studies revealed that TIGAR staining was increased in colorectal tumor compared to adjacent normal tissue. The strong positive staining is significantly higher in early stage (I and II) colorectal cancer $(p<0.05)$ as well as in the late stage colorectal cancer $(p<0.01)$. TIGAR staining in all tumors are found to be concentrated in the nucleus. TIGAR expression has been shown to be increased in colon cancer (13). However, TIGAR expression has not been reported in various stages of colorectal cancer. This study finds TIGAR overexpression in various stages of colorectal cancer in a different ethnic group involving colorectal cancer patients from Saudi Arabia. This overexpression of TIGAR may help to support survival of colorectal cancer cells.

Our finding indicates the TIGAR staining is increased in both early and late stage colorectal cancer. TIGAR mRNA is significantly expressed in stage II and stage III colorectal cancer. TIGAR expression is involved in the progression of colorectal malignancies as evident by TIGAR expression in the early stage of colorectal cancer.

The biosynthesis metabolic pathway provides intermediates for cell growth during malignant progression. The p53-induced activation of TIGAR leads to an antioxidant response that promotes cell survival $(6,25,26)$. In this study, TIGAR protein is found to be highly expressed in colorectal tumor tissues and CRC cell lines. TIGAR protein was found to be increased in stage II and III colorectal cancer as compared to normal adjacent tissue. TIGAR protein was also highly expressed in metastatic samples. These results are consistent with earlier report that found that TIGAR was significantly expressed in colon adenocarcinoma and metastasis (13). This detection of TIGAR expression in early stage colorectal cancer with respect to earlier report (13) may be due to different ethnicity with distinct genetic mutations. TIGAR expression in early stage can help to support transformation by inducing increased proliferation of abnormal lesion in the colon. TIGAR expression is equally distributed from colorectal adenocarcinoma cell 
line in HT-29 and HCT116 to Dukes' type C cell line HCT-15 and metastatic colorectal cancer cell line SW620. Some studies have shown TIGAR as a potential target for radiosensitization and cell death of cancer cells. TIGAR knockdown resulted in radiosensitisation in glioma cells through an accumulation of ROS, leading to DNA damage and cellular senescence (8).

In conclusion, TIGAR is upregulated in colorectal cancer patients from Saudi Arabia. TIGAR is highly expressed at the mRNA and protein levels in stage II and stage III colorectal cancer. TIGAR protein is also widely expressed in CRC cell lines. Thus, the high expression of TIGAR protein in various stages of colorectal cancer may be used for the detection of colorectal cancer. Overexpression of TIGAR can act as an attractive target for developing therapeutics for treating colorectal cancer. More studies with higher sample size specifically comprised of early stages are needed for better understanding of molecular mechanism of TIGAR expression possibly making TIGAR a biomarker for early detection of colorectal cancer.

\section{Acknowledgments}

The authors would like to thank the Vice Deanship Research Chair, Deanship of Scientific Research, King Saud University for supporting this study. This study was financially supported by King Saud University, through Vice Deanship of Research Chairs.

\section{References}

1. Lao VV and Grady WM: Epigenetics and colorectal cancer. Nat Rev Gastroenterol Hepatol 8: 686-700, 2011.

2. Lin L, Piao J, Gao W, Piao Y, Jin G, Ma Y, Li J and Lin Z: DEK over expression as an independent biomarker for poor prognosis in colorectal cancer. BMC Cancer 13: 366, 2013.

3. Pitule P, Vycital O, Bruha J, Novak P, Hosek P, Treska V, Hlavata I, Soucek P, Kralickova M and Liska V: Differential expression and prognostic role of selected genes in colorectal cancer patients. Anticancer Res 33: 4855-4865, 2013.

4. Vousden KH and Lu X: Live or let die: The cell's response to p53. Nat Rev Cancer 2: 594-604, 2002.

5. Jen KY and Cheung VG: Identification of novel p53 target genes in ionizing radiation response. Cancer Res 65: 7666-7673, 2005.

6. Bensaad K, Tsuruta A, Selak MA, Vidal MN, Nakano K, Bartrons R, Gottlieb E and Vousden KH: TIGAR, a p53-inducible regulator of glycolysis and apoptosis. Cell 126: 107-120, 2006.

7. Kimata M, Matoba S, Iwai-Kanai E, Nakamura H, Hoshino A, Nakaoka M, Katamura M, Okawa Y, Mita Y, Okigaki M, et al: p53 and TIGAR regulate cardiac myocyte energy homeostasis under hypoxic stress. Am J Physiol Heart Circ Physiol 299: H1908-H1916, 2010.

8. Peña-Rico MA, Calvo-Vidal MN, Villalonga-Planells R, Martínez-Soler F, Giménez-Bonafé P, Navarro-Sabaté À, Tortosa A, Bartrons R and Manzano A: TP53 induced glycolysis and apoptosis regulator (TIGAR) knockdown results in radiosensitization of glioma cells. Radiother Oncol 101: 132-139, 2011.
9. Yin L, Kosugi M and Kufe D: Inhibition of the MUC1-C oncoprotein induces multiple myeloma cell death by down-regulating TIGAR expression and depleting NADPH. Blood 119: 810-816, 2012.

10. Lui VW, Lau CP, Cheung CS, Ho K, Ng MH, Cheng SH, Hong B, Tsao SW, Tsang CM, Lei KI, et al: An RNA-directed nucleoside anti-metabolite, 1-(3-C-ethynyl-beta-d-ribo-pentofuranosyl) cytosine (ECyd), elicits antitumor effect via TP53-induced glycolysis and apoptosis regulator (TIGAR) downregulation. Biochem Pharmacol 79: 1772-1780, 2010.

11. Wanka C, Steinbach JP and Rieger J: Tp53-induced glycolysis and apoptosis regulator (TIGAR) protects glioma cells from starvation-induced cell death by up-regulating respiration and improving cellular redox homeostasis. J Biol Chem 287: 33436-33446, 2012.

12. Ye L, Zhao X, Lu J, Qian G, Zheng JC and Ge S: Knockdown of TIGAR by RNA interference induces apoptosis and autophagy in HepG2 hepatocellular carcinoma cells. Biochem Biophys Res Commun 437: 300-306, 2013.

13. Cheung EC, Athineos D, Lee P, Ridgway RA, Lambie W, Nixon C, Strathdee D, Blyth K, Sansom OJ and Vousden KH: TIGAR is required for efficient intestinal regeneration and tumorigenesis. Dev Cell 25: 463-477, 2013.

14. Cooper HS, Murthy SN, Shah RS and Sedergran DJ: Clinicopathologic study of dextran sulfate sodium experimental murine colitis. Lab Invest 69: 238-249, 1993.

15. Won KY, Lim SJ, Kim GY, Kim YW, Han SA, Song JY and Lee DK: Regulatory role of p53 in cancer metabolism via SCO2 and TIGAR in human breast cancer. Hum Pathol 43: 221-228, 2012.

16. Sinha S, Ghildiyal R, Mehta VS and Sen E: ATM-NFkB axis-driven TIGAR regulates sensitivity of glioma cells to radiomimetics in the presence of TNF $\alpha$. Cell Death Dis 4: e615, 2013.

17. Lui VW, Wong EY, Ho K, Ng PK, Lau CP, Tsui SK, Tsang CM, Tsao SW, Cheng SH, Ng MH, et al: Inhibition of c-Met downregulates TIGAR expression and reduces NADPH production leading to cell death. Oncogene 30: 1127-1134, 2011.

18. Barker N, Ridgway RA, van Es JH, van de Wetering M, Begthel H, van den Born M, Danenberg E, Clarke AR, Sansom OJ and Clevers H: Crypt stem cells as the cells-of-origin of intestinal cancer. Nature 457: 608-611, 2009.

19. Rimm DL, Camp RL, Charette LA, Costa J, Olsen DA and Reiss M: Tissue microarray: A new technology for amplification of tissue resources. Cancer J 7: 24-31, 2001.

20. Bu XD, Li N, Tian XQ, Li L, Wang JS, Yu XJ and Huang PL: Altered expression of MUC2 and MUC5AC in progression of colorectal carcinoma. World J Gastroenterol 16: 4089-4094, 2010.

21. Alam M, Rajabi H, Ahmad R, Jin C and Kufe D: Targeting the MUC1-C oncoprotein inhibits self-renewal capacity of breast cancer cells. Oncotarget 5: 2622-2634, 2014.

22. Ahmad R, Raina D, Trivedi V, Ren J, Rajabi H, Kharbanda S and Kufe D: MUC1 oncoprotein activates the IkappaB kinase beta complex and constitutive NF-kappaB signalling. Nat Cell Biol 9: 1419-1427, 2007.

23. Vogelstein B, Lane D and Levine AJ: Surfing the p53 network. Nature 408: 307-310, 2000.

24. Matoba S, Kang JG, Patino WD, Wragg A, Boehm M, Gavrilova O, Hurley PJ, Bunz F and Hwang PM: p53 regulates mitochondrial respiration. Science 312: 1650-1653, 2006.

25. Budanov AV, Sablina AA, Feinstein E, Koonin EV and Chumakov PM: Regeneration of peroxiredoxins by p53-regulated sestrins, homologs of bacterial AhpD. Science 304: 596-600, 2004

26. Cosentino C, Grieco D and Costanzo V: ATM activates the pentose phosphate pathway promoting anti-oxidant defence and DNA repair. EMBO J 30: 546-555, 2011. 